\title{
MicroRNAs in Search of a Target
}

\author{
G. SteFani AND F. Slack \\ Department of Molecular, Cellular and Developmental Biology, Yale University, New Haven, Connecticut 06520
}

\begin{abstract}
As the number of known microRNAs (miRNAs) increases, and their importance in physiology and disease becomes apparent, the identification of their regulatory targets is a requisite for a full characterization of their biological functions. Computational methods based on sequence homology and phylogenetic conservation have spearheaded this effort in the last 3 years, but they may not be sufficient. Experimental studies are now needed to extend and validate the computational predictions and further our understanding of target recognition by miRNAs.
\end{abstract}

The discovery of miRNAs has provided a paradigm shift in our understanding of gene regulation and has set the scene for the discovery of exciting novelties in this area. The idea that RNA has the capability of performing a large array of functions dates back to the early days of molecular biology in the 1960s, and RNA has since proven itself to be a highly versatile molecule, most strikingly with the discovery and characterization of ribozymes. It is the unexpected breadth of miRNA-mediated regulation of gene expression that has conferred a "revolutionary" character to its discovery (Novina and Sharp 2004). The number of known miRNAs has rapidly escalated since the discovery by genetic analysis of lin-4 and let-7 in Caenorhabditis elegans (Lee et al. 1993; Wightman et al. 1993; Pasquinelli et al. 2000; Reinhart et al. 2000). Although approximately 470 human miRNAs appear in the registry at the time of this review, and current estimations suggest that $30 \%$ of human genes are regulated by miRNAs, recent bioinformatic studies hint at the existence of tens of thousands of short noncoding RNAs similar to miRNAs, with the potential to regulate the expression of virtually all human genes (Farh et al. 2005; Rigoutsos et al. 2006).

As in the case for transcription factors and RNA-binding proteins, the classic protein trans-regulators of gene expression, the elucidation of the biological roles of miRNAs requires the identification of target genes, a task that presents specific challenges.

\section{ROLE OF MIRNA IN GENE REGULATION: FROM SWITCHES TO RHEOSTATS}

The observation of rather profound phenotypes in $C$. elegans larval development led to the discovery of lin-4 and let-7, the first animal miRNAs to be characterized (Lee et al. 1993; Wightman et al. 1993; Reinhart et al. 2000). The mutation of the heterochronic gene lin-4 was known to lead to reiterations of the cell lineage specific to stage 1 larvae (Chalfie et al. 1981), and molecular characterization of lin-4 by positional cloning led to the identification of mutations that abolished the expression of a short, noncoding RNA (Lee et al. 1993). Forward genetics also provided the identity of the lin-4 target
mRNA, as it was known from previous screenings that the heterochronic phenotype of lin-4 was due to loss of negative regulation of lin-14 (Ambros 1989). Thus, lin-14 became the first known miRNA target (Lee et al. 1993; Wightman et al. 1993). The availability of a genetically validated target allowed researchers to define two important features of miRNA-mediated gene regulation that were to be confirmed in numerous cases in the following years: First, the repression of target genes happens posttranscriptionally, as the levels of lin-14 mRNA were shown to remain largely unchanged after the disappearance of LIN-14 protein (Wightman et al. 1993). Second, the repression was carried out through a direct interaction of the miRNA with its target mRNA's 3'UTR (untranslated region), as shown by the presence of imperfect complementary sites and by the identification of lin-14 gain-of-function mutants with partial deletions of their 3'UTR (Wightman et al. 1991, 1993). Analogously, the discovery of the second miRNA in animals, let-7, was prompted by the observation of reiterations of larval cell fates and an even more profound temperature-sensitive adult phenotype associated with vulva bursting (Reinhart et al. 2000). Genetic observations also drove the identification of lin-41 as a let-7 target, thus providing an additional substrate for mechanistic studies that confirmed the posttranscriptional mode of regulation of miRNAs through annealing to the 3'UTRs of their targets (Vella et al. 2004b). Unlike lin-4, let-7 was found to have obvious orthologous genes in other phyla, including vertebrates and humans (Pasquinelli et al. 2000). Thus, let-7 became the first discovered human miRNA. This finding triggered biochemical efforts aimed to clone new miRNAs in invertebrates and vertebrates from sizefractionated RNA samples (Lagos-Quintana et al. 2001; Lau et al. 2001; Lee and Ambros 2001). The biochemical identification of dozens of new miRNAs showed that, as in the case of lin-4 and let-7, the vast majority of mature miRNAs are surrounded by regions that can fold into a hairpin structure. This feature provided a set of rules that allowed bioinformatic searches of vertebrate genomes, leading to the current estimate of hundreds of miRNAs in the human genome (Lim et al. 2003a). Hundreds of miRNAs have been isolated by biochemical and 
bioinformatic approaches, but no genetic information is available for them, and their mRNA targets are unknown. Bioinformatic methods have been the main tool for the identification of miRNA target mRNA and have led to a picture of the biological role of miRNA that differs in some respect from the role delineated by the earlier genetic observations. Although lin-4 and let-7 repress the expression of their targets to inconsequential levels, much like a switch, it has now been proposed that miRNAs also act like a rheostat, modulating the expression of their targets to an optimal level (Bartel and Chen 2004). Functions such as the reduction of the stochastic noise of gene expression or the refinement of borders between domains of gene expression are proposed tasks of miRNAs (Bartel and Chen 2004).

Some of these early predictions have been validated experimentally in the last 3 years. Single miRNAs have been shown to target many mRNAs, and the 3'UTRs of many mRNAs harbor potential recognition sites for numerous miRNAs, in agreement with a mode of regulation that is both promiscuous and modular (Lewis et al. 2005; Lim et al. 2005). Genetic deletions of single miRNAs in different organisms can show subtle or undetectable phenotypes, suggesting functional redundancy among miRNAs (Abbott et al. 2005). Furthermore, recent studies have elucidated an interesting role of miRNA in shaping the evolution of the 3'UTR sequence (Farh et al. 2005; Stark et al. 2005; Sood et al. 2006). Evolutionarily conserved and nonconserved miRNA complementary sequences are equally effective in mediating gene repression when inserted in a reporter and artificially coexpressed with a targeting miRNA (Farh et al. 2005). Interestingly, the nonconserved miRNA complementarity sites (which are the vast majority) are present in genes that are not coexpressed with the matching miRNAs, whereas mRNAs carrying the less abundant conserved sites are clearly coexpressed with miRNAs, albeit at lower levels (Farh et al. 2005; Sood et al. 2006). Therefore, genes carrying miRNA sites in their 3'UTR would seem to avoid coexpression with targeting miRNAs, whereas genes expressed at high levels are depleted of sequences recognizable by coexpressed miRNAs. These findings have been interpreted as a sign of evolutionary pressure exerted by miRNAs on the 3'UTR of target mRNAs: Only those miRNA-mRNA interactions that are advantageous or neutral to the cell are retained during evolution, whereas detrimental miRNA-matching sequences arising by random mutations are selected against in the genes that are coexpressed with the corresponding miRNAs. On the contrary, the generation of a complementary site by random mutation, a relatively frequent event since the complementarity was defined by only seven uninterrupted matching residues in these studies, is essentially evolutionarily neutral in the absence of the corresponding miRNA, thus explaining the observed abundance of miRNA complementary sites and the lack of evolutionary conservation (Farh et al. 2005; Stark et al. 2005; Sood et al. 2006).

The advancement in the understanding of the biological role of miRNAs has been impressive in the mere 6 years since their discovery in vertebrates, but some important aspects of miRNA-mediated gene regulation are still missing. In particular, the ability to accurately identify targets of miRNAs is still poor due to the lack of in vivo empirical data on miRNA-target interactions and reliable physical experimental methods.

\section{THE ISSUE OF TARGET IDENTIFICATION: CHALLENGES IN BIOINFORMATIC PREDICTION}

The importance of target mRNA sequence recognition through sites of imperfect complementarity was demonstrated early in the history of the discovery of miRNAs (Wightman et al. 1991, 1993; Lee et al. 1993). Computational search for complementary sequences in the genomes was the only practical method for the identification of miRNA regulatory targets. Unlike in plants, where a high level of complementarity between miRNAs and their targets makes the search relatively straightforward, the presence of a variable level of mismatches in animal miRNA-target pairs poses challenges to the computational identification of targets. Furthermore, computational biologists trying to predict targets for hundreds of newly discovered miRNAs could only count on a very restricted training set: Only five miRNA-mRNA pairs were biologically validated, offering merely 23 examples of miRNA recognition sites (Lewis et al. 2003; Stark et al. 2003). Nonetheless, the set of rules that were obtained from the small available set of targets proved to be very useful in designing first-pass efficient computational search strategies. The first programs designed for the identification of miRNA targets relied on a set of assumptions about the mechanism of target recognition by miRNAs, most notably the requirement for a perfect match between residues 2 and 8 at the $5^{\prime}$ end of the miRNA and the $3^{\prime}$ end of the complementary site on the target mRNA (alternatively referred to as "seed," "core," or "nucleus") (Lewis et al. 2003; Rajewsky and Socci 2004). Several observations supported this assumption: (1) The available set of biologically validated examples mostly shared this feature; (2) residues 2-8 are the most conserved among orthologous miRNAs (Lewis et al. 2003; Lim et al. 2003b); (3) sequence motifs previously known to be able to mediate posttranscriptional regulation of gene expression, the $\mathrm{K}$ box and Brd box, were complementary to the $5^{\prime}$ end of miRNAs (Lai 2002). The importance of a perfect match in the "seed" region was directly verified through experiments carried out in tissue culture cells transfected with luciferase reporters (Doench and Sharp 2004). Nonetheless, the emphasis on the importance of the perfect match in the "seed" region might obscure some aspects of the mechanism of target sequence recognition by miRNAs. In the well-characterized example of let-7-mediated repression of lin-41, the complementary "seed" region is interrupted by a bulge that is required for function in one of the two let-7 complementarity sites (LCS), and the integrity of the region between the two sites is required for regulation, hinting at a possible role for secondary structure of the lin-41 3'UTR or involvement of other trans factors (Vella et al. 2004a,b). 
A computational search for new targets of let-7 that allowed extended complementary regions in the $3^{\prime}$ end of let-7 to compensate for mismatches in the "seed" region yielded 12 new targets that were validated both genetically and by analysis of reporters in transgenic animals (Grosshans et al. 2005; Johnson et al. 2005). A recent study rigorously assessed the requirements of sequence complementarity between miRNA and their targets using transgenic reporters in the context of the Drosophila wing imaginal disc (Brennecke et al. 2005). Two classes of miRNA-mRNA interactions were defined: " 5 ' dominant," with an uninterrupted stretch of seven nucleotides corresponding to the $5^{\prime}$ end of the miRNA, followed by a variable degree of complementarity in the 3 ' end; and ' 3 ' compensatory" sites, which have weak $5^{\prime}$ base-pairing and depend on strong compensatory pairing to the $3^{\prime}$ end of the miRNA (Brennecke et al. 2005). The former class is estimated to outnumber the second class by approximately one order of magnitude (Brennecke et al. 2005). Recent bioinformatic programs that were developed to take into account these findings and that used broader comparisons between newly sequenced genomes yield more extensively overlapping sets of predicted targets (for review, see Rajewsky 2006).

Despite the impressive progress achieved through computational methods, many miRNA regulatory interactions might still be undetected, and false positives are likely. A recent search for conserved motifs in the 3'UTR of various mammalian genomes was able to identify conserved sites matching about half of the known miRNAs; no conserved matching sites were found for the other half, even allowing one mismatch and T-G pairing in the first eight nucleotides (Xie et al. 2005). These findings suggest that interactions between a large number of miRNAs and their targets elude the predictive ability of current computational methods. This is not surprising considering that although all computational methods treat miRNAs and their targets essentially as naked RNA, miRNAs are part of a large multimolecular complex, the miRISC (RNA-induced silencing complex), which conceivably could affect their accessibility to the regulatory targets (for review, see Valencia-Sanchez et al. 2006). The mRNA targets, on the other hand, are also mostly associated with multiple proteins, which regulate many aspects of gene expression (Dreyfuss et al. 2002). Although computational methods have been invaluable for our current understanding of miRNAs, novel genetic and biochemical approaches are needed to identify targets and to provide a better insight into their biological role.

\section{THE ISSUE OF TARGET IDENTIFICATION: CHALLENGES IN EXPERIMENTAL APPROACHES}

The difficulties in experimentally identifying miRNA regulatory targets stem from the lack of comprehensive knowledge of their mechanism of action. A number of different mechanisms of repression have been proposed. The disappearance of lin-14-encoded protein in the presence of a steady level of lin-14 mRNA suggested initially that lin-4 was acting as an inhibitor of translation (Wightman et al. 1993). The presence of the repressed lin-14 and lin-28 mRNA in the polyribosomal fractions of a linear density gradient led to the hypothesis that miRNAs regulate a step of translation subsequent to initiation (Olsen and Ambros 1999; Seggerson et al. 2002). Three recent studies revisited this issue and reached discordant conclusions: Evidence was provided in agreement with miRNA inhibition at a postinitiation step of translation, but evidence was also found of miRNA regulation at the initiation step (Humphreys et al. 2005; Pillai et al. 2005; Petersen et al. 2006). The implications of the two opposing models are relevant to the issue of miRNA target identification: If miRNAs inhibit the initiation step of translation, the abundance of the regulated mRNA targets is expected to be low in the polyribosome fraction. It would then be feasible to identify regulatory targets by purifying mRNA from the polyribosome fraction, which represents the pool of mRNA that is undergoing active translation, and use it to synthesize probes for microarrays. One would expect the abundance of target mRNAs to be increased in the absence of a specific miRNA. This strategy has been used successfully to identify the targets of $m i R-30 a-3 p$ (Nakamoto et al. 2005). A similar strategy has proven to be successful in the identification of mRNAs whose expression is modulated by various RNA-binding proteins or in response to different treatments (Johannes et al. 1999; Zong et al. 1999; Brown et al. 2001; Arava et al. 2003; Galban et al. 2003; Preiss et al. 2003; Rajasekhar et al. 2003; Schratt et al. 2004; Dinkova et al. 2005). On the other hand, if miRNAmediated regulation is at postinitiation steps, the level of target mRNA could not change sufficiently to be detected by this approach.

Other recently proposed mechanisms of miRNAmediated regulation involve sequestration of target mRNAs in P bodies. Evidence in favor of this mechanism includes the colocalization of miRISC components and miRNAs in P bodies and disruption of both P-body integrity and miRNA-mediated gene regulation as a consequence of dominant-negative forms of miRISC or P-body components (Ding et al. 2005; Jakymiw et al. 2005; Liu et al. 2005a,b). P bodies were originally discovered as intracellular locations dedicated to mRNA decapping and degradation, but subsequent studies have shown that the sequestration of mRNAs in the $\mathrm{P}$ bodies can be temporary and reversible (Sheth and Parker 2003; Brengues et al. 2005; Bhattacharyya et al. 2006). These findings are reconciled with the evidence of miRNA-mediated translational inhibition in a model where, as inhibition of translation occurs, the mRNA targeted by the miRISC-miRNA complex is sequestered in the P bodies. Depending on the intrinsic features of the mRNA and on the level of sequence complementarity with the targeting miRNA, the sequestered mRNA can undergo a variable level of decapping, deadenylation, and degradation (for review, see Zamore and Haley 2005; Valencia-Sanchez et al. 2006). In agreement with this model, several studies now show that miRNA-mediated control results in reduction of the steady-state abun- 
dance of regulated mRNAs (Yekta et al. 2004; Bagga et al. 2005; Jing et al. 2005). Degradation of the target mRNAs seems to involve a mechanism distinct from siRNA-mediated silencing, as cleavage sites have been mapped outside the region of complementarity, and deadenylation seems to initiate the degradation process (Bagga et al. 2005; Giraldez et al. 2006; Wu et al. 2006). Despite the difficulty of reconciling the conflicting findings on the mechanisms of miRNAmediated translational inhibition and degradation, measuring the steady-state abundance of total mRNAs has become one of the most common methods of experimentally identifying potential miRNA targets (Farh et al. 2005; Lim et al. 2005; Giraldez et al. 2006). Although this experimental strategy has been useful in validating mRNA targets that were predicted by bioinformatic methods, it has a limited ability to identify new regulatory targets. One limitation is the inability to distinguish between direct regulation by a specific miRNA and indirect effects: Indeed, most measurements of this kind have shown a roughly equal number of increased and decreased mRNAs. Furthermore, this methodology fails to identify genes that are primarily regulated at the level of translation. Genes that are regulated by miRNAs in the absence of significant changes in corresponding mRNA abundance have been documented, as have reporter experiments in which miRNAs repress translation without relevant degradation of the mRNA (Saxena et al. 2003; Zeng et al. 2003; Chen 2004; Doench and Sharp 2004; Poy et al. 2004; Cimmino et al. 2005; Johnson et al. 2005; O'Donnell et al. 2005; Pillai et al. 2005).

\section{POSSIBLE SOLUTIONS}

The challenges of understanding the biological roles of miRNAs are not unfamiliar to the field of gene regulation. In many respects, the proposed roles of miRNAs are not dissimilar to the known activities of other transacting regulators of gene expression, such as splicing and transcription factors. Like small nuclear RNAs (snRNA), which recruit the small nuclear ribonucleoprotein (snRNP) complexes U1 and U2 to specific sites of the intron through imperfect annealing, miRNAs target a protein effector complex, the miRISC, to a specific target sequence. The analogy can also be extended to protein trans-gene regulators, such as transcription factors and RNA-binding protein, which recognize a large variety of target sequences through specific contacts between their amino acid residues and the nucleic acid bases. Although the identification of regulatory transcription factors, given a bona fide promoter or enhancer defined through functional assays, has been relatively straightforward using DNA affinity purification, the reverse task, i.e., the identification of DNA target sequences for a given transcription factor, has only recently become experimentally tractable in a reliable way. Until the advent of chromatin immunoprecipitation (ChIP) techniques, in vitro selection experiments would yield short, high-affinity, DNA-binding sequences for a candidate transcription factor that were then used for computational searches in the available genomic databases. Methods based purely on searching for consensus sequences were obviously inadequate, as the association of transcription factor to DNA is a complex phenomenon: Genomic DNA is tightly packed in chromatin structures that modulate its accessibility, and transcription factors themselves are often part of higher-order complexes with other proteins, such as chromatin modification and remodeling complexes and the basic machinery of transcription, which affects their DNA-binding specificity in vivo. ChIP, especially when conjugated to DNA microarray technology, accounts for the complexity of such intermolecular contacts by providing a snapshot of protein-DNA interactions in the living cell. Analogously, although not to the same extent yet, similar approaches based on the copurification of trans-regulatory factors and their target sequences are having a growing impact on our understanding of posttranscriptional gene regulation, in particular RNA splicing. Similarly, to further our understanding of the biological functions of miRNAs, novel experimental methodologies aimed at identifying miRNA targets in vivo are in dire need. A possible strategy is the aforementioned analysis of polysomal pools of mRNAs. Another method would be the copurification of target mRNA with the miRISC complex, or with the $\mathrm{P}$ bodies, and then comparing cells or organisms where an miRNA is blocked or mutated with untreated or wild-type ones (RIP/ChIP). Genomewide in vivo approaches of this kind could eventually feed useful information back to the computational biologists and allow new and more predictive bioinformatic methods to emerge.

Since their discovery, the perception of miRNAs has changed from a gene regulation phenomenon limited to plants and C. elegans to an almost universal level of gene regulation, thanks largely to computational studies. Now, some 15 years later, the ball is back in the experimental biologist's court.

\section{ACKNOWLEDGMENTS}

We thank Diya Banerjee for critical reading of this manuscript and suggestions.

\section{REFERENCES}

Abbott A.L., Alvarez-Saavedra E., Miska E.A., Lau N.C., Bartel D.P., Horvitz H.R., and Ambros V. 2005. The let-7 microRNA family members mir-48, mir-84, and mir-241 function together to regulate developmental timing in Caenorhabditis elegans. Dev. Cell 9: 403.

Ambros V. 1989. A hierarchy of regulatory genes controls a larvato-adult developmental switch in C. elegans. Cell 57: 49.

Arava Y., Wang Y., Storey J.D., Liu C.L., Brown P.O., and Herschlag D. 2003. Genomewide analysis of mRNA translation profiles in Saccharomyces cerevisiae. Proc. Natl. Acad. Sci. 100: 3889.

Bagga S., Bracht J., Hunter S., Massirer K., Holtz J., Eachus R., and Pasquinelli A.E. 2005. Regulation by let-7 and lin-4 miRNAs results in target mRNA degradation. Cell 122: 553.

Bartel D.P. and Chen C.Z. 2004. Micromanagers of gene expression: The potentially widespread influence of metazoan microRNAs. Nat. Rev. Genet. 5: 396.

Bhattacharyya S.N., Habermacher R., Martine U., Closs E.I., 
and Filipowicz W. 2006. Relief of microRNA-mediated translational repression in human cells subjected to stress. Cell 125: 1111.

Brengues M., Teixeira D., and Parker R. 2005. Movement of eukaryotic mRNAs between polysomes and cytoplasmic processing bodies. Science 310: 486.

Brennecke J., Stark A., Russell R.B., and Cohen S.M. 2005. Principles of microRNA-target recognition. PLoS Biol. 3: e85.

Brown V., Jin P., Ceman S., Darnell J.C., O’Donnell W.T., Tenenbaum S.A., Jin X., Feng Y., Wilkinson K.D., Keene J.D., et al. 2001. Microarray identification of FMRP-associated brain mRNAs and altered mRNA translational profiles in fragile X syndrome. Cell 107: 477.

Chalfie M., Horvitz H.R., and Sulston J.E. 1981. Mutations that lead to reiterations in the cell lineages of C. elegans. Cell 24: 59 .

Chen X. 2004. A microRNA as a translational repressor of APETALA2 in Arabidopsis flower development. Science 303: 2022.

Cimmino A., Calin G.A., Fabbri M., Iorio M.V., Ferracin M., Shimizu M., Wojcik S.E., Aqeilan R.I., Zupo S., Dono M., et al. 2005. miR-15 and miR-16 induce apoptosis by targeting BCL2. Proc. Natl. Acad. Sci. 102: 13944.

Ding L., Spencer A., Morita K., and Han M. 2005. The developmental timing regulator AIN-1 interacts with miRISCs and may target the argonaute protein ALG-1 to cytoplasmic P bodies in C. elegans. Mol. Cell 19: 437.

Dinkova T.D., Keiper B.D., Korneeva N.L., Aamodt E.J., and Rhoads R.E. 2005. Translation of a small subset of Caenorhabditis elegans mRNAs is dependent on a specific eukaryotic translation initiation factor 4E isoform. Mol. Cell. Biol. 25: 100.

Doench J.G. and Sharp P.A. 2004. Specificity of microRNA target selection in translational repression. Genes Dev. 18: 504 .

Dreyfuss G., Kim V.N., and Kataoka N. 2002. Messenger-RNAbinding proteins and the messages they carry. Nat. Rev. Mol. Cell Biol. 3: 195.

Farh K.K., Grimson A., Jan C., Lewis B.P., Johnston W.K., Lim L.P., Burge C.B., and Bartel D.P. 2005. The widespread impact of mammalian microRNAs on mRNA repression and evolution. Science 310: 1817.

Galban S., Fan J., Martindale J.L., Cheadle C., Hoffman B., Woods M.P., Temeles G., Brieger J., Decker J., and Gorospe M. 2003. von Hippel-Lindau protein-mediated repression of tumor necrosis factor alpha translation revealed through use of cDNA arrays. Mol. Cell. Biol. 23: 2316.

Giraldez A.J., Mishima Y., Rihel J., Grocock R.J., Van Dongen S., Inoue K., Enright A.J., and Schier A.F. 2006. Zebrafish MiR-430 promotes deadenylation and clearance of maternal mRNAs. Science 312: 75.

Grosshans H., Johnson T., Reinert K.L., Gerstein M., and Slack F.J. 2005. The temporal patterning microRNA let-7 regulates several transcription factors at the larval to adult transition in C. elegans. Dev. Cell 8: 321

Humphreys D.T., Westman B.J., Martin D.I., and Preiss T. 2005. MicroRNAs control translation initiation by inhibiting eukaryotic initiation factor 4E/cap and poly(A) tail function. Proc. Natl. Acad. Sci. 102: 16961

Jakymiw A., Lian S., Eystathioy T., Li S., Satoh M., Hamel J.C., Fritzler M.J., and Chan E.K. 2005. Disruption of GW bodies impairs mammalian RNA interference. Nat. Cell Biol. 7: 1267.

Jing Q., Huang S., Guth S., Zarubin T., Motoyama A., Chen J., Di Padova F., Lin S.C., Gram H., and Han J. 2005. Involvement of microRNA in AU-rich element-mediated mRNA instability. Cell 120: 623.

Johannes G., Carter M.S., Eisen M.B., Brown P.O., and Sarnow P. 1999. Identification of eukaryotic mRNAs that are translated at reduced cap binding complex eIF4F concentrations using a cDNA microarray. Proc. Natl. Acad. Sci. 96: 13118.

Johnson S.M., Grosshans H., Shingara J., Byrom M., Jarvis R., Cheng A., Labourier E., Reinert K.L., Brown D., and Slack F.J. 2005. RAS is regulated by the let-7 microRNA family. Cell 120: 635.
Lagos-Quintana M., Rauhut R., Lendeckel W., and Tuschl T. 2001. Identification of novel genes coding for small expressed RNAs. Science 294: 853.

Lai E.C. 2002. Micro RNAs are complementary to 3'UTR sequence motifs that mediate negative post-transcriptional regulation. Nat. Genet. 30: 363.

Lau N.C., Lim L.P., Weinstein E.G., and Bartel D.P. 2001. An abundant class of tiny RNAs with probable regulatory roles in Caenorhabditis elegans. Science 294: 858.

Lee R.C. and Ambros V. 2001. An extensive class of small RNAs in Caenorhabditis elegans. Science 294: 862

Lee R.C., Feinbaum R.L., and Ambros V. 1993. The C. elegans heterochronic gene lin-4 encodes small RNAs with antisense complementarity to lin-14. Cell 75: 843 .

Lewis B.P., Burge C.B., and Bartel D.P. 2005. Conserved seed pairing, often flanked by adenosines, indicates that thousands of human genes are microRNA targets. Cell 120: 15.

Lewis B.P., Shih I.H., Jones-Rhoades M.W., Bartel D.P., and Burge C.B. 2003. Prediction of mammalian microRNA targets. Cell 115: 787.

Lim L.P., Glasner M.E., Yekta S., Burge C.B., and Bartel D.P. 2003a. Vertebrate microRNA genes. Science 299: 1540.

Lim L.P., Lau N.C., Weinstein E.G., Abdelhakim A., Yekta S., Rhoades M.W., Burge C.B., and Bartel D.P. 2003b. The microRNAs of Caenorhabditis elegans. Genes Dev. 17: 991-1008.

Lim L.P., Lau N.C., Garrett-Engele P., Grimson A., Schelter J.M., Castle J., Bartel D.P., Linsley P.S., and Johnson J.M. 2005. Microarray analysis shows that some microRNAs downregulate large numbers of target mRNAs. Nature 433: 769.

Liu J., Valencia-Sanchez M.A., Hannon G.J., and Parker R. 2005a. MicroRNA-dependent localization of targeted mRNAs to mammalian P-bodies. Nat. Cell Biol. 7: 719.

Liu J., Rivas F.V., Wohlschlegel J., Yates J.R., III, Parker R., and Hannon G.J. 2005b. A role for the P-body component GW182 in microRNA function. Nat. Cell Biol. 7: 1261.

Nakamoto M., Jin P., O’Donnell W.T., and Warren S.T. 2005. Physiological identification of human transcripts translationally regulated by a specific microRNA. Hum. Mol. Genet. 14: 3813.

Novina C.D. and Sharp P.A. 2004. The RNAi revolution. Nature 430: 161

O’Donnell K.A., Wentzel E.A., Zeller K.I., Dang C.V., and Mendell J.T. 2005. c-Myc-regulated microRNAs modulate E2F1 expression. Nature 435: 839.

Olsen P.H. and Ambros V. 1999. The lin-4 regulatory RNA controls developmental timing in Caenorhabditis elegans by blocking LIN-14 protein synthesis after the initiation of translation. Dev. Biol. 216: 671 .

Pasquinelli A.E., Reinhart B.J., Slack F., Martindale M.Q., Kuroda M.I., Maller B., Hayward D.C., Ball E.E., Degnan B., Muller P., et al. 2000. Conservation of the sequence and temporal expression of let-7 heterochronic regulatory RNA. Nature 408: 86.

Petersen C.P., Bordeleau M.E., Pelletier J., and Sharp P.A. 2006. Short RNAs repress translation after initiation in mammalian cells. Mol. Cell 21: 533 .

Pillai R.S., Bhattacharyya S.N., Artus C.G., Zoller T., Cougot N., Basyuk E., Bertrand E., and Filipowicz W. 2005. Inhibition of translational initiation by Let-7 MicroRNA in human cells. Science 309: 1573.

Poy M.N., Eliasson L., Krutzfeldt J., Kuwajima S., Ma X., Macdonald P.E., Pfeffer S., Tuschl T., Rajewsky N., Rorsman P., and Stoffel M. 2004. A pancreatic islet-specific microRNA regulates insulin secretion. Nature 432: 226.

Preiss T., Baron-Benhamou J., Ansorge W., and Hentze M.W. 2003. Homodirectional changes in transcriptome composition and mRNA translation induced by rapamycin and heat shock. Nat. Struct. Biol. 10: 1039.

Rajasekhar V.K., Viale A., Socci N.D., Wiedmann M., Hu X., and Holland E.C. 2003. Oncogenic Ras and Akt signaling contribute to glioblastoma formation by differential recruitment of existing mRNAs to polysomes. Mol. Cell 12: 889 .

Rajewsky N. 2006. microRNA target predictions in animals. Nat. Genet. (suppl. 1) 38: S8. 
Rajewsky N. and Socci N.D. 2004. Computational identification of microRNA targets. Dev. Biol. 267: 529.

Reinhart B.J., Slack F.J., Basson M., Pasquinelli A.E., Bettinger J.C., Rougvie A.E., Horvitz H.R., and Ruvkun G. 2000. The 21-nucleotide let-7 RNA regulates developmental timing in Caenorhabditis elegans. Nature 403: 901.

Rigoutsos I., Huynh T., Miranda K., Tsirigos A., McHardy A., and Platt D. 2006. Short blocks from the noncoding parts of the human genome have instances within nearly all known genes and relate to biological processes. Proc. Natl. Acad. Sci. 103: 6605 .

Saxena S., Jonsson Z.O., and Dutta A. 2003. Small RNAs with imperfect match to endogenous mRNA repress translation. Implications for off-target activity of small inhibitory RNA in mammalian cells. J. Biol. Chem. 278: 44312.

Schratt G.M., Nigh E.A., Chen W.G., Hu L., and Greenberg M.E. 2004. BDNF regulates the translation of a select group of mRNAs by a mammalian target of rapamycin-phosphatidylinositol 3-kinase-dependent pathway during neuronal development. J. Neurosci. 24: 7366.

Seggerson K., Tang L., and Moss E.G. 2002. Two genetic circuits repress the Caenorhabditis elegans heterochronic gene lin-28 after translation initiation. Dev. Biol. 243: 215.

Sheth U. and Parker R. 2003. Decapping and decay of messenger RNA occur in cytoplasmic processing bodies. Science 300: 805 .

Sood P., Krek A., Zavolan M., Macino G., and Rajewsky N. 2006. Cell-type-specific signatures of microRNAs on target mRNA expression. Proc. Natl. Acad. Sci. 103: 2746.

Stark A., Brennecke J., Russell R.B., and Cohen S.M. 2003. Identification of Drosophila microRNA targets. PLoS Biol. 1: E60.

Stark A., Brennecke J., Bushati N., Russell R.B., and Cohen S.M. 2005. Animal microRNAs confer robustness to gene expression and have a significant impact on 3'UTR evolution. Cell 123: 1133.
Valencia-Sanchez M.A., Liu J., Hannon G.J., and Parker R. 2006. Control of translation and mRNA degradation by miRNAs and siRNAs. Genes Dev. 20: 515.

Vella M.C., Reinert K., and Slack F.J. 2004a. Architecture of a validated microRNA::target interaction. Chem. Biol. 11: 1619.

Vella M.C., Choi E.Y., Lin S.Y., Reinert K., and Slack F.J. 2004b. The C. elegans microRNA let-7 binds to imperfect let7 complementary sites from the lin-41 3'UTR. Genes Dev. 18: 132 .

Wightman B., Ha I., and Ruvkun G. 1993. Posttranscriptional regulation of the heterochronic gene lin- 14 by lin- 4 mediates temporal pattern formation in C. elegans. Cell 75: 855 .

Wightman B., Burglin T.R., Gatto J., Arasu P., and Ruvkun G. 1991. Negative regulatory sequences in the lin-14 3'-untranslated region are necessary to generate a temporal switch during Caenorhabditis elegans development. Genes Dev. 5: 1813.

Wu L., Fan J., and Belasco J.G. 2006. MicroRNAs direct rapid deadenylation of mRNA. Proc. Natl. Acad. Sci. 103: 4034.

Xie X., Lu J., Kulbokas E.J., Golub T.R., Mootha V., LindbladToh K., Lander E.S., and Kellis M. 2005. Systematic discovery of regulatory motifs in human promoters and 3'UTRs by comparison of several mammals. Nature 434: 338.

Yekta S., Shih I.H., and Bartel D.P. 2004. MicroRNA-directed cleavage of HOXB8 mRNA. Science 304: 594.

Zamore P.D. and Haley B. 2005. Ribo-gnome: The big world of small RNAs. Science 309: 1519.

Zeng Y., Yi R., and Cullen B.R. 2003. MicroRNAs and small interfering RNAs can inhibit mRNA expression by similar mechanisms. Proc. Natl. Acad. Sci. 100: 9779.

Zong Q., Schummer M., Hood L., and Morris D.R. 1999. Messenger RNA translation state: The second dimension of high-throughput expression screening. Proc. Natl. Acad. Sci. 96: 10632 . 


\section{$8_{\mathrm{CSH}}^{\infty}$ Cold Spring Harbor Symposia SYMPOSIA}

\section{MicroRNAs in Search of a Target}

G. STEFANI and F. SLACK

Cold Spring Harb Symp Quant Biol 2006 71: 129-134

Access the most recent version at doi:10.1101/sqb.2006.71.032

References This article cites 69 articles, 30 of which can be accessed free at: http://symposium.cshlp.org/content/71/129.full.html\#ref-list-1

\section{License}

Email Alerting Receive free email alerts when new articles cite this article - sign up in Service the box at the top right corner of the article or click here. 